\title{
INFECÇÃO EXPERIMENTAL DE CALOMYS CALLOSUS (RODENTIA-CRICETIDAE) COM LEISHMANIA DONOVANI CHAGASI (LAISON, 1982)*
}

Dalva A. Mello**

Maria Lucia Teixeira***

\begin{abstract}
MELLO, D. A. \& TEIXEIRA, M. L. Infeçção experimental de Calomys callosus (Rodentia-Cricetidae) com Leishmania donovani chagasi (Laison, 1982). Rev. Saúde públ., S. Paulo, 18: 337 - 41, 1984.
\end{abstract}

RESUMO: Foi descrita a infecção experimental em Calomys callosus com uma cepa de Leishmania donovani chagesi de caso humano. Um grupo de 22 roedores foi inoculado por via intraperitoneal com $0,1 \mathrm{ml}$ de um macerado de baço em salina, rico em amastigotas. Esses animais foram sacrificados três meses após as inoculaçőes, tendo sido realizado: cultura "in vitro" em meio acelular (LIT e NNN) e esfregaços, corados pelo Giemsa, de fígado, baço, medula óssea e sangue; cortes histológicos corados com hematoxilina-eosina de fígado e baço. Os resultados para fígado e baço foram: $67 \%$ de positividade nas culturas "in vitro"; esfregaços ricos em amastigotas intra e extra celular (inclui medula óssea); reaçóes teciduais traduzidas por hepatomegalia com proliferaç̃o das células de Kupffer; reação granulomatosa das áreas portais, esplenomegalia com reaçōes granulomatosas, abundância de formas amastigotas. Os resultados para o sangue foram negativos $\mathrm{em}$ todas as investigaçoes.

UNITERMOS: Calomys callosus. Leishamania donovani. Infecção experimental.

\section{INTRODUÇÃO}

Calomys callosus é um roedor silvestre de ampla distribuição geográfica no Brasil. (Moojen $^{16}$, 1952 e Mello e Moojen ${ }^{13}, 1979$ ) tendo se adaptado com sucesso ao cativeiro (Mello $^{8}$, 9, 11 , 1977, 1978, 1981). Estudos experimentais em $C$. callosus, nascidos no cativeiro, com microorganismos patogênicos, foram realizados por Justines e Johnson ${ }^{6}$ (1969), Borba ${ }^{2}$ (1972), Mello e col. ${ }^{15}$ (1979), Mello ${ }^{10}$ (1979/80), Mello e Borges ${ }^{14}$ (1981), Borges e Mello ${ }^{3}$ (1980) e Borges e Kloetzel $^{4}$ (1982). Esses autores trabalharam com virus da febre hemorrágica, Schistosoma mansoni, Leishmania mexicana, Plasmo- dium berghei e Trypanosoma cruzi. Os resultados das suas pesquisas mostraram a potencialidade desse roedor como modelo experimental com microorganismos de interesse médico.

Embora $L$. donovani, agente do calazar tenha como modelos experimentais em laboratório, camundongo e hamster, procurou-se no trabalho aqui apresentado, estudar a capacidade de $C$. callosus em se infectar com este parasita. A pesquisa foi justificada no sentido de ampliar os conhecimentos sobre esse roedor e como uma alternativa de outro modelo experimental para essa parasitose.

* Trabalho apresentado no Congresso Integrado de Parasitologia, São Paulo, 4-8 setembro de 1983.

** Do Centro de Ciências da Saúde da Universidade Federal de São Carlos - Via Washington Luiz Km 235 - 13560 - São Carlos, SP - Brasil.

*** Da Universidade de Brasília - Caixa Postal 15.3031 - 70000 - Brasília, DF - Brasil 
MELLO, D. A. \& TEIXEIRA, M. L. Infecção experimental de Calomys callosus (Rodentia-Cricetidae) com Leishmania donovani chagasi (Laison, 1982). Rev. Saúde públ., S. Paulo, 18: 337 - 41, 1984.

\section{MATERIAL E MÉTODOS}

\section{Seleção dos Animais}

Vinte e dois $C$. callosus, 7 machos e 15 fêmeas, com 2 meses de idade e peso médio de $26,5 \mathrm{~g} .( \pm 2,3)$, originados de um plantel adaptado ao cativeiro desde 1975 (Mel$10^{12}, 1983$ ), foram utilizados na pesquisa.

\section{Procedência da Amostra de $L$. d. chagasi,} utilizada na pesquisa.

A amostra de $L$. d. chagasi foi isolada de um paciente com 51 anos, residente no município de Imperatriz, Estado do Maranhão. Esta amostra vinha sendo mantida no laboratório através de inoculações em hamster. Antes de se iniciar os experimentos a amostra de $L$. $d$. chagasi foi adaptada ao $C$. callosus, após duas passagens sucessivas de inoculos de "pool" de baço de hamster.

\section{Procedimento do Experimento}

Os $C$. callosus foram inoculados com $0,1 \mathrm{ml}$ de um homogeneizado em salina estéril, de baço de animal homólogo, rico em formas amastigotas. Esses animais foram guardados e observados no laboratório, sendo sacrificados após três meses de inoculados, quando estavam então com 5 meses de idade e pesando em média $29,7 \mathrm{~g}$. $( \pm-2,9)$. Foram retirados fígado e baço, pesados e comparados àqueles de animais sadios. Fragmentos desses órgãos foram fixa. dos em formol $10 \%$ para confecção de cortes histológicos, corados com hematoxilina-eosina. Foram realizados esfregaços por aposição de fígado, baço e medula óssea e estiramento de sangue, corados pela Giemsa. Cultivo "in vitro", em meio acelular (LIT e NNN), foi realizado para sangue, fígado e baço.

\section{RESULTADOS E COMENTÁRIOS}

Todos os animais inoculados foram positivos à infeç̧ão por $L$. d. chagasi.

Os pesos de fígado e baço dos animais infectados, comparados com animais normais, estão incisos na Tabela. Observa-se que o aumento de fígado e baço, traduzido em grama, foi bastante acentuado, caracterizando hepato e esplenomegalias.

Foi diagnosticada a presença de numerosas formas amastigotas, intra e extracelular, em todos os esfregaços de medula óssea, fígado e baço. Houve positividade nas cultu. ras de baço e fígado em $67 \%$ dos animais. 0 s resultados foram negativos para o sangue, quer no que se refere a cultura quer no que se refere aos esfregaços.

Os achados histológicos foram os seguin. tes: Baço - a estrutura deste órgão está representada por uma distribuição difusa $e$ compacta de células mononucleares. 0 grau de parasitismo celular varia de moderado a severo; há presença de inúmeros macrófagos

T A B E L A

Pesos médios corporal, de fígado e baço de Calomys callosus normal e infectado experimentalmente com Leishmania donovani

\begin{tabular}{|c|c|c|c|}
\hline \multirow[t]{2}{*}{ C. callosus } & \multicolumn{3}{|c|}{ Pesos Médios } \\
\hline & $\begin{array}{l}\text { Corporal } \\
\text { (gI) }\end{array}$ & $\begin{array}{c}\text { Fígado } \\
\text { (mg) }\end{array}$ & $\begin{array}{l}\text { Baço } \\
\text { (mg) }\end{array}$ \\
\hline Normal & $30,9( \pm 2,6)$ & $1,243( \pm 0,088)$ & $0,033( \pm 0,015)$ \\
\hline Infectado & $29,7( \pm 2,9)$ & $2,075( \pm 0,457)$ & $0,791( \pm 0,032)$ \\
\hline Diferença & 1,2 & 0,832 & 0,758 \\
\hline
\end{tabular}


MELLO, D. A. \& TEIXEIRA, M. L. Infecção experimental de Calomys callosus (Rodentia-Cricetidae) com Leishmania donovani chagasi (Laison, 1982). Rev. Saúde públ., S. Paulo, 18:337 - 41, 1984.

vacuolados contendo formas amastigotas no citoplasma, observando-se ocasionalmente a formação de reação granulomatosa (Fig. 1); fígado - neste órgão foram encontrados extensos infiltrados mononucleares com proliferação de células de Kupffer parasitadas, a formação de reação granulomatosa com células gigantes multinucleadas, principalmente ao nível dos espaços porta; nesses infiltrados, que penetram e destroem o parênquima hepático, notam-se hepatócitos com sinais degenerativos $\mathrm{e}$ inúmeras figuras de mitose (Fig. 2 e 3).

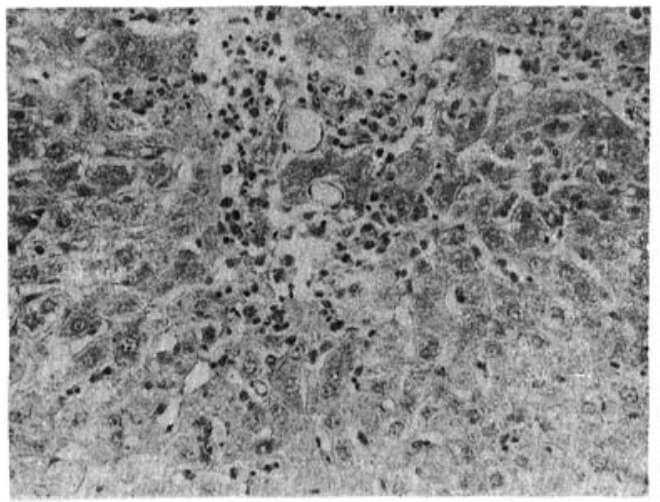

Fig. 2 Histopatologia do fígado de Calomys cal. losus, infectado com Leishmania donova. $n i$. Infiltrado mononuclear com célula contendo ninho de formas amastigotas.

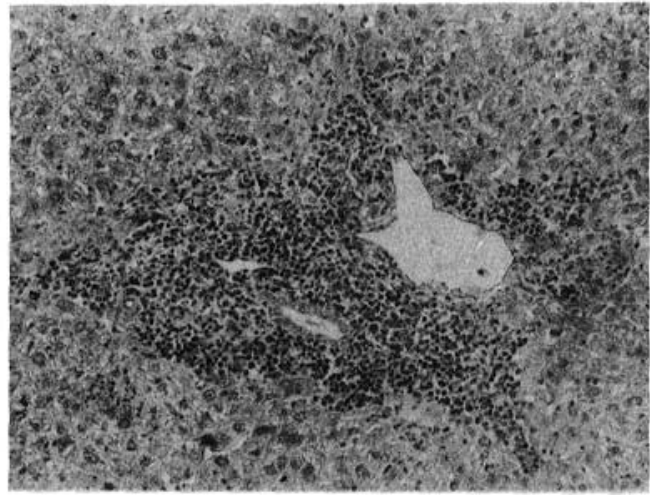

Fig. 1 - Histopatologia do fígado de Calomys cal. losus, infectado com Leishmania dono. vani, mostrando o espaço porta com extenso infiltrado mononuclear.

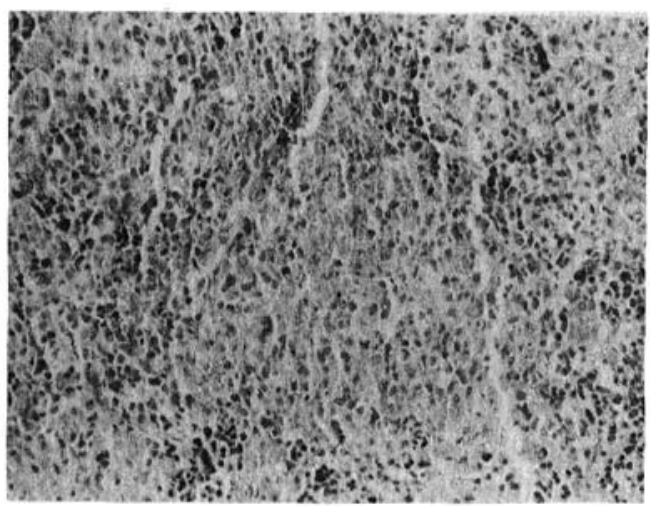

Fig. 3 - Baço de Calomys callosus, infectado com Leishmania donovani, altamente parasitado.
O primeiro trabalho sobre roedores silvestres $\mathrm{e}$ infecção experimental por $L$. $d$. chagasi foi realizado por Adler e 1 heodor ${ }^{1}$ (1931). Esses autores estudaram Microtus guntheri que se mostrou espécie bastante suscetivel apresentando baço hipertrofiado e altamente rico em formas amastigotas. $\mathrm{Grun}^{5}$ (1958) apresentou resultados promissores com Meriones unguiculatus. Stauber e col. $^{18}$ (1966), trabalhando com Arvicanthis niloticus niloticus, mostraram ser essa espécie de roedor tão suscetível quanto o hamster. Observaram hepato e esplenomegalia sendo esses órgãos altamente parasitados. No entanto, para o sangue, os resultados sempre foram negativos. Ranque e col. $^{17}$ (1974) mostraram que Arvicanthis niloticus, espécie encontrada naturalmente infectada por $L$. donovani, também se presta a estudos experimentais com esse protozoário. $O$ parasita invade as vísceras, sendo a medula e o baço, locais em que se encontra maior quantidade de formas mastigotas. Esses autores mostraram também que os jovens eram mais suscetíveis do que os adultos. Krampitz e $\mathrm{col}^{7}$, (1977) estudaram Clethrionomys glareolus, o qual se mostrou bom hospedeito experimental para $L$. donovani. 
MELLO, D. A. \& TEIXEIRA, M. L. Infecção experimental de Calomys callosus (Rodentia-Cricetidae) com Leishmania donovani chagasi (Laison, 1982). Rev. Saúde públ., S. Paulo, 18:337 - 41, 1984.

As experiências que aqui foram conduzidas indicam que a exemplo dos trabalhos acima mencionados, $C$. callosus poderia também se prestar a estudos experimentais com L. donovani. Acrescenta-se ainda que esse cricetídeo é um animal que se adapta bem às condições de cativeiro, seu manejo não apresenta dificuldade e atinge boa produtividade (Mello $\left.{ }^{12}, 1983\right)$.

MELLO, D. A. \& TEIXEIRA, M. L. [Experimental infection of Calomys callosus (Rodentia-Cricetidae) with Leishmania donovani]. Rev. Saúde públ., São Paulo, 18:337 - 41, 1984.

ABSTRACT: In the current paper experimental infection of Calomys callosus with Lei. shmania donovani is reported for the first time. A group of $22 \mathrm{C}$. callosus aged 20 months and weighing $25 \mathrm{~g}$ were inoculated with 0.1 of a homogeneous saline preparation of infected spleens of homologous animals. The $L$. donovani strain used in the experiments was isolated from a case of human visceral leishmaniasis from the state of Maranhão, Brazil. The animals infected were weighed and killed 3 months after the experimental infection. Spleens and livers were also weighed and pieces from them were fixed in $10 \%$ formaline and stained with hematoxilin-eosin for histological studies. Impression smears stained with Giemsa were made and cultivation "in vitro" (NNN and LIT) was done, with material from blood, spleen, liver and bone marrow. At the end of the experiments the animals showed low of body weight. Splenomegaly was observed in all the inoculated animals. The "in vitro" cultures were positive from liver and spleen in 67\% of the animals. Many extracellular and intracellular amastigote forms were seen in the smears of spleen, liver and bone marrow. Blood showed negative results. Histological studies of the liver showed proliferation of Kupffer cells and granulomatous reaction in the portal areas with multinucleated cells and amastigote forms of the parasites. Loss of folicular pattern with parasitism in great numbers of cells around which there were granulomatous reactions were observed in the spleen.

UNITERMS: Calomys callosus. Leishmania donovani. Experimental infection.

\section{REFERÊNCIAS BIBLIOGRÁFICAS}

1. ADLER, S. \& THEODOR, O. Investigations on Mediterranean kala-azar. II - Leishmania in. fantum. Proc. roy. Soc. London, 108: 453$-502,1931$.

2. BORBA, C. E. Infecção natural e experimental de alguns roedores pelo Schistosoma manso. ni Sambon, 1907. Belo Horizonte, 1972. [Dissertação de Mestrado - Departamento de Parasitologia do ICB da UFMG]

3. BORGES, M. M. \& MELLO, D. A. Infectividade de cepas silvestres de Trypanosoma cruzi mantidas em culturas, para Calomys callosus (Rodentia) e camundongos albinos. Rev. Patol. trop., 9: 145-51, 1980.

4.BORGES, M. M. \& KLOETZEL, J. Course of Trypanosoma cruzi infection in irradiated Calomys callosus (Rodentia-Cricetidae). In: Reuniẫo Anual de Pesquisas Básicas em Doenças de Chagas, Caxambu, MG, 1982. Resumos. Caxambu, MG, 1982. p. 46.
5.GRUN, J. A study of experimental leishmaniasis in the mouse mongolian gerbil, hamster, white rat, cotton rat and chinchilla, 1958. PhD Thesis, Rutgers - The state University. Apud Stauber, L. A. ${ }^{18}$

6.JUSTINES, G. \& JOHNSON, K. M. Immune tolerance in Calomys callosus infected with machupo virus. Nature, 222: 1090-1, 1969.

7. KRAMPITZ, H. E.; WEBER, B. \& SCHEFFER, K. Zum Vertalten von Leishmanien aus Hautulzera des Manschen in Kleinen Labortieren. Acta Trop., 34: 293-311, 1977.

8. MELLO, D. A. Note on breeding of Calomys callosus, Lund, 1841 (Rodentia, Cricetidae) under laboratory conditions. Rev. bras. Pesq. med. biol., 10: 107, 1977.

9.MELLO, D. A. Biology of Calomys callosus (Rengger, 1830) under laboratory conditions 
MELLO, D. A. \& TEIXEIRA, M. L. Infecção experimental de Calomys callosus (Rodentia-Cricetidae) com Leishmania donovani chagasi (Laison, 1982). Rev. Saúde públ., S. Paulo, 18:337 - 41, 1984.

(Rodentia, Cricetidae), Rev. bras. Biol., 38: 807-11, 1978.

10.MELLO, D. A. Infeç̧ão experimental de Calo. mys callosus (Rengger, 1830) (Cricetidae-Rodentia) a quatro espécies de parasitas. Rev. Soc. bras. Med. trop., 13: 101-5, 1979/80.

11.MELLO, D. A. Studies on reproduction and longevity of Calomys callosus under laboratory conditions (Rodentia, Cricetidae). Rev. bras. Biol., 41: 841-3, 1981.

12. MELLO, D. A. Calomys callosus Rengger, 1830 (Rodentia-Cricetidae): sua caracterização, distribuição, biologia, criação e manejo de uma cepa em laboratório. Mem. Inst. Oswaldo Cruz, 79: 37-44, 1984.

13.MELLO, D. A. \& MOOJEN, L. E. Nota sobre uma coleção de roedores e marsupiais de algumas regiōes do cerrado do Brasil Central. Rev. bras. Pesq. med. biol, 12: 287-91, 1979.

14.MELLO, D. A. \& BORGES, M. M. Primeiro encontro do Triatoma costalimai naturalmente infectado pelo Trypanosoma cruzi: estudo de aspectos biológicos da amostra isolada. Mem. Inst. Oswaldo Cruz, 76: 61-9, 1981.
15. MELIO, D. A.; VALIN, E. \& TEIXEIRA, M. L. Alguns aspectos do comportamento de cepas silvestres de Trypanosoma cruzi em camundongos e Calomys callosus. Rev. Saúde públ., S. Paulo, 13: 31425, 1979.

16. MOOJEN, J. Os roedores do Brasil. Rio de Janeiro. Ministério de Educação e Saúde, 1952. (Biblioteca Científica Brasileira - Série A II 1-A).

17. RANQUE, P.; QUILICI, M. \& CAMERLYNCK, P. Arvicanthis niloticus (Rongeur, Muridé), reservoir de virus de base de Leishmaniose au Senegal. Bull. Soc. Path. exot., 67: 167 $-75,1974$.

18. STAUBER, L. A.; McCONNELL, E. \& HOOGSTRAAL, H. Leishmaniasis in the Sudan Republic, 25. Experimental visceral leishmaniasis in the Nile Grass Rat, Arvicanthis nilo. ticus niloticus Dollman. Exper. Parasit., 18: $35-40,1966$.

Recebido para publicação em 08/11/1983 Reapresentado em 09/05/1984 Aprovado para publicaçāo em 18/05/1984 